\title{
Solar Resource Assessment study for Pakistan
}

\author{
Steffen Stökler ${ }^{a}$, Christoph Schillings $^{a}$ and Birk Kraas ${ }^{b}$ \\ ${ }^{a}$ German Aerospace Center (DLR), System Analysis and Technology Assessment, Wankelstr. 5, 70567 \\ Stuttgart, Germany \\ ${ }^{\mathrm{b}} \mathrm{CSP}$ Services GmbH, Paseo de Almería 73, 2, 04001 Almeria, Spain \\ Corresponding author:
}

Tel. +49 (0) 7116862483

Steffen Stökler (steffen.stoekler@dlr.de)

\section{Abstract}

Solar resource assessment becomes more and more a very important factor for planners of Photovoltaic (PV) and Concentrated Solar Power (CSP) plants nowadays. Choice between nearby locations can make the difference if a plant is profitable or not, especially in a versatile climatic region with complex topography as it can be found in Pakistan. Nevertheless, Pakistan's geographic location and climate offers a very high potential for solar energy applications. The solar resource assessment study presented in this article describes the approach and set-up required by the World Bank's Energy Sector Management Assistance Program (ESMAP) $)^{l}$ : The presented project described, aims on creating a validated solar atlas for Pakistan based on a combination of satellite data and ground measurements to support country-driven efforts to improve renewable energy resource awareness and exploitation. There are several country-specific, ESMAP-funded projects conducted by the World Bank Group (WBG) that cover comprehensive mapping and geospatial planning, including ground-based data collection. The solar resource estimation of Pakistan was one of the first projects to be approved within the program and leads the way for the solar assessments in other countries.

The final and validated dataset ultimately will be published in the International Renewable Energy Agencies' (IRENA) global atlas for renewable energy ${ }^{2}$.

\footnotetext{
${ }^{1}$ Further details are available at https://www.esmap.org/ and http://www.esmap.org/RE Mapping (02/2015)

${ }^{2}$ Further details are available at http://www.irena.org/globalatlas/ (02/2015)
} 


\section{Introduction}

Mapping national renewable energy (RE) resources is a crucial step in expanding investment into clean energy, by providing governments with the information necessary to strategically guide commercial development, establish pricing incentives, and take account of environmental and social constraints ${ }^{3}$. The Energy Sector Management Assistance Program of the World Bank supports RE mapping on countrywide scale within its Clean Energy Program framework. For several countries RE mapping projects are established to provide the information on available resources. This paper gives an overview on the solar project activities in Pakistan.

Pakistan is blessed with abundant renewable energy resources including wind, solar, biomass, geothermal, hydro etc. Some previous ground-based data has been collected for wind and also for solar insolation ([1] Adnan et al., 2012). Although the results of previous studies delivered very promising outcomes ([2] Perez et al., 2007, [1] Adnan et al., 2012 and commercial products), an up-to-date long-term satellite estimation, validated with ground measured data that covers the solar irradiance for the whole country, does not exist. This lack of reliable and validated country-wide data is addressed with the ESMAP solar resource mapping project for Pakistan.

The objective of this activity is to support the sustainable expansion of electricity generation from solar power by providing the Government of Pakistan and commercial developers with an improved understanding of the spatial distribution and potential of solar resources at country level.

This information will be contained in the main output of the project, a solar atlas containing monthly and annual values of Global Horizontal (GHI) and Direct Normal Irradiance (DNI). High resolution data of geostationary satellites will be used to create the solar atlas. This data will be validated by using nine ground measurement stations installed during this project at various sites all over Pakistan. The measurement sites are set up in certain locations to cover a variety of typical solar regimes.

Within the three-year project, three phases of solar resource assessment are covered.

- Phase 1: Preliminary modeling using satellite data only: Preparation of an initial solar resource estimate for Pakistan based on solar radiation modeling using satellite and reanalysis data.

\footnotetext{
${ }^{3}$ Information provided by http://www.esmap.org/RE_Mapping (02/2015)
} 
- Phase 2: 24-months ground measurement period at nine selected sites: Implementation of a ground-based measurement campaign using high quality solar measurement devices, with real-time data transmission and reporting, for the purpose of validating and improving the initial solar resource maps and for generating reliable benchmarking data.

- Phase 3: Establishment of the validated solar atlas: Validated solar resource maps and a solar atlas report which describes the final outputs, methodology and process, and includes provision of the final data to be used in a Geographical Information System (GIS).

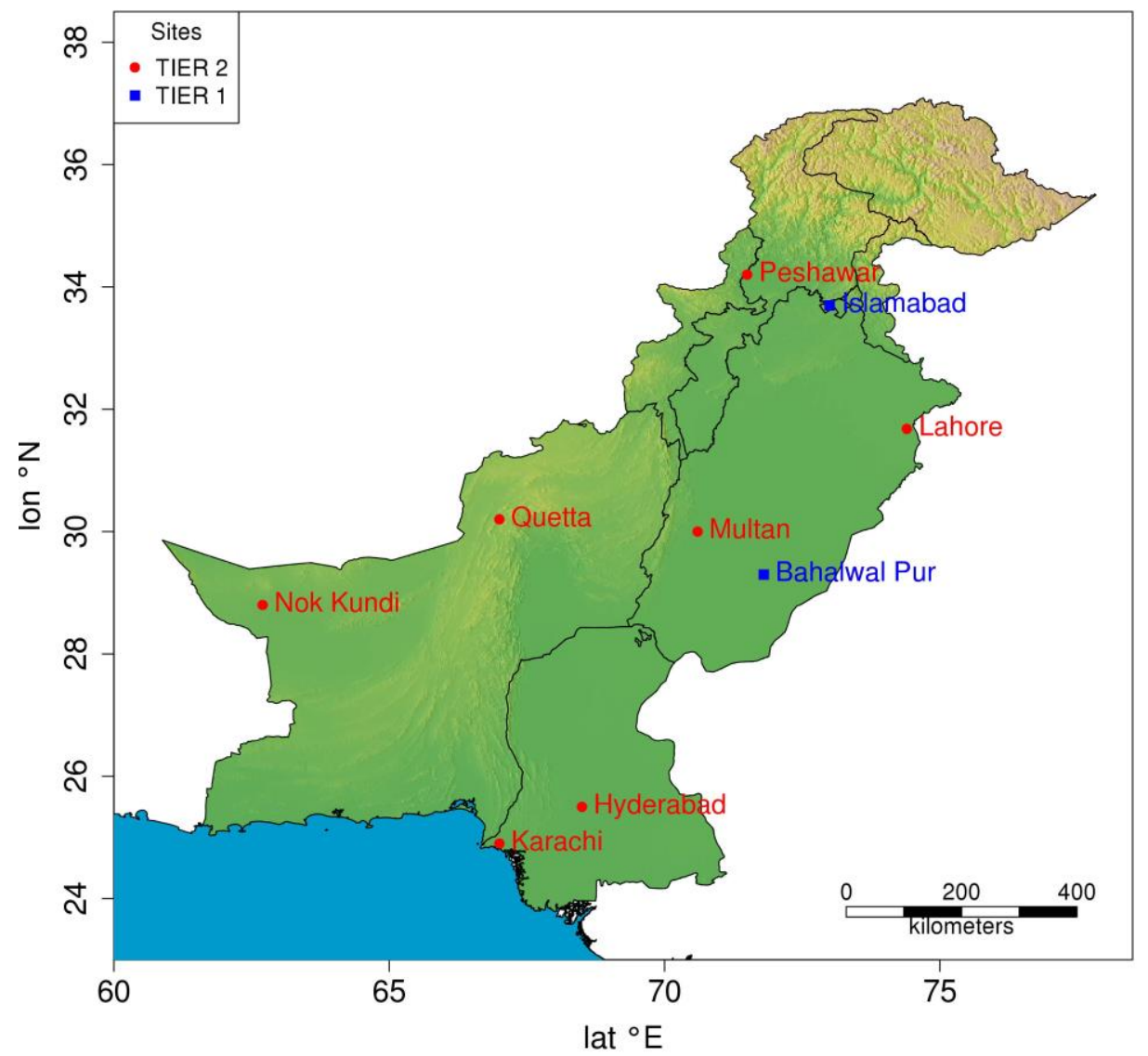

Figure 1: Location of Measurement sites for validation purposes in Phase 3 of the project. 


\section{Project outline}

\subsection{General approach}

Pakistan covers an area of more than $800.000 \mathrm{~km}^{2}$ and is divided into several, heterogeneous geographic regions. Remote sensing data on its own may not cover all of these versatile landscapes in the same quality. Using precision data from measurement stations alone neither will lead to a satisfactory solar resource assessment in a country wide study, even if the stations are maintained and cleaned regularly. [3] Perez et al. (1997) have demonstrated that interpolation/extrapolation between measurement stations leads to less accurate results than satellite models do, once the distance between the stations exceeds 34 $\mathrm{km}$. This distance is likely to be less, as satellites, satellite models and atmospheric input parameters have improved since this study. Perez also accentuated that it would need at least 800 ground stations (on $100 \mathrm{~km}$ grid) for the U.S.A. to outmatch the performance of satellites ([3] Perez et al., 1997). If transferred to the area of Pakistan, at least 65-70 well maintained measurement stations would have been needed in operation since the year 2000 to surpass the satellite model's performance.

For this reason, surface measurement stations are used to validate the satellite data in different locations, combining the advantages of high-precision pinpoint measurements with the availability of multi-year spatial data from satellite. For this study, nine sites are set up throughout the country (Figure 1). The locations of these measurement sites have been selected in a multi-criteria selection process, involving local partners and project stakeholders. In a first step, solar regimes were identified that exhibit the highest possible differences in annual sums of solar irradiance as well as high differences in intra-annual irradiance values, based on monthly sums. This is to evaluate the performance of the used satellite-based method in a wide range of different climatological locations. Each of the identified solar regimes has to be provided with at least one ground measurement site. In a second step, input from local partners and stakeholders was collected and evaluated. This included availability of maintenance staff and host organizations for the measurement stations, socio-economic considerations and the probability of long-term sustainable use of the measurement stations after the project duration. To achieve this sustainability, training of local staff in operation and maintenance of the measurement equipment, as well as in understanding and evaluating the data, is a strong focus in the ESMAP project. Point-wise validation by using data of the measurement sites will lead to an improvement of the spatial data in Phase 3 of the study. This methodology will lead to a better understanding of meteorological processes and possible systematic satellite model deviations for each of the solar regimes, as it is widely transferable to the entirety of the respective solar regimes' area. 


\subsection{Used Data}

As stated above, primary data sources are satellite-based and ground-based. During Phase 1 and Phase 3 of the project satellite-based data is processed. Preliminary results of Phase 1 resource assessment are presented in this article. Phase 2 is a two-year period where surface measurements of solar irradiance are conducted. Once this measurement data is gathered it will be used to evaluate the quality of satellite data processed in Phase 1 and, if necessary, an adaptation of this data will be performed in Phase 3 before it is integrated in the global atlas.

\section{Satellite data}

Pakistan is fully covered by the Meteosat-7 (Met-7) satellite, which is positioned $57.5^{\circ} \mathrm{E}$ Indian Ocean Data Coverage (IODC) in a geostationary orbit in 36.000 km above the earth's surface. Met-7 is operational since November 2006 and was preceded by Meteosat- 5 (Met5 ), which was positioned $63^{\circ} \mathrm{E}$. Both satellites are identical, so homogeneity of the data is ensured. Meteosat-5 data is available from the end of 1999 , so a 13 -year dataset (20002012 ) is the output period of Phase 1 within the study. The final validated solar atlas will ultimately contain monthly and annual averaged sums of solar radiation based on hourly data of the years 2000 to 2017, which represents the complete period of the IODC. The computational method to process the downward solar irradiance in use is the Heliosat-2Method (eg. [4] Hammer et al., 2003, [5] Rigollier et al., 2004, an improvement of the original Heliosat method by [6] Cano et al., 1986). The resulting irradiance data of DNI, GHI and DIF is based on global atmospheric data sets (aerosol, water vapor, ozone) from different earth observation sources.

Daily climatology for the Aerosol Optical Depth (AOD) is available from the NASA/DLR Model of Atmospheric Transport and Chemistry (MATCH) or the ECMWF Monitoring Atmospheric Composition and Climate (MACC) model. The MATCH-dataset has an original spatial resolution of $1.9^{\circ} \times 1.9^{\circ}$, increased to $0.5^{\circ} \times 0.5^{\circ}$ by bilinear interpolation. The MACC dataset is available in its $1.25^{\circ} \times 1.25^{\circ}$ original resolution and is available from the year 2003 onwards. Furthermore, water vapor data derived from the NCEP/NCAR-Reanalysis of the Climate Diagnostic Center (CDC-NOAA) is used with a monthly temporal resolution and a $2.5^{\circ} \times 2.5^{\circ}$ spatial resolution. Ozone data input is derived from the Total Ozone Mapping Spectrometer (TOMS) and is available in monthly values and a $1^{\circ} \times 1.25^{\circ}$ spatial resolution.

\section{Ground measurements}

For the ground measurement campaign, high-precision thermopile solar irradiance sensors for daily maintained reference site (Tier 1 station, 2 sites), and Rotating Shadowband Irradiometer (RSI) for remote sites (Tier 2 station, 7 sites) are used. Measured parameters 
are direct, global and diffuse irradiance, ambient temperature, air humidity and pressure, wind speed and direction with a sampling rate of $10 \mathrm{~min}$. The instruments are equipped for remote data transfer via GPRS network. Tier 1 specifications comply with ISO and WMO (World Meteorological Organization) performance criteria (ie. Baseline Surface Radiation Network, BSRN), the RSI sensors used on Tier 2 are widely used in solar energy industry and provide good accuracy combined with high data availability.

Tier 1 station: Meteorological Measurement Station for high-precision irradiance data at well maintained sites with electricity grid connection. DNI measurements with ISO 9060 First Class Pyrheliometer, GHI and DHI measured with ISO 9060 secondary standard pyranometers, mounted on a highly accurate automatic sun tracker with active tracking control. Data collection is conducted via GPRS, according to BSRN standards. Measurement uncertainty is approximately $1 \%$ for daily DNI and $<2 \%$ for daily GHI values (see Table 1 ).

Tier 2 station: Meteorological Measurement Station appropriate for self-sufficient operation at remote locations, equipped with Rotating Shadowband Irradiometer (RSI). Data collection is also conducted via GPRS. Typically a measurement uncertainty of $<3 \%$ for daily irradiation values is reached (see Table 1).

\begin{tabular}{|c|c|c|}
\hline \multicolumn{3}{|c|}{ TIER 1} \\
\hline Sensor Type & Measured Quantity & $\begin{array}{c}\text { Expected daily } \\
\text { uncertainty }\end{array}$ \\
\hline Pyrheliometer CHP 1 & DNI (Direct Normal Irradiation) & $\pm 1 \%$ \\
\hline $\begin{array}{c}\text { Pyranometer CMP } 21 \\
\text { (shaded) }\end{array}$ & DHI (Diffuse Horizontal Irradiation) & $\pm 2 \%$ \\
\hline Pyranometer CMP 21 & GHI (Global Horizontal Irradiation) & $\pm 2 \%$ \\
\hline \multicolumn{3}{|c|}{ TIER 2} \\
\hline \multirow[t]{2}{*}{$\begin{array}{l}\text { RSI with LI-COR Pyranometer } \\
\text { with full calibration }\end{array}$} & GHI (Global Horizontal Irradiation) & $\begin{array}{l}\text { Instant. }>4 \% \\
\text { Annual }>3 \%\end{array}$ \\
\hline & DHI (Diffuse Horizontal Irradiation) & \\
\hline
\end{tabular}




\begin{tabular}{|l|c|c|}
\hline DNI (Direct Normal Irradiation) & $\begin{array}{c}\text { Instant. }>3.5 \% \\
\text { Annual }>2 \%\end{array}$ \\
\hline
\end{tabular}

Table 1: Measurement accuracy of stations set up in Pakistan.

\subsection{Validation of model}

Once the ground measurement period is completed and the ground- and satellite data is quality checked, the validation phase is initiated. There are some options to adapt irradiance data to measured datasets. The first step is the adaption via different aerosol models. Clearsky cases (ie. cloud-free days) are chosen to evaluate the impact of the different aerosol models and to select the model with the best performance. Aerosol datasets will also validated against measured data of the Aerosol Robotic Network (AERONET) to achieve the most accurate results possible, as a high aerosol- and dust-load can be found in the atmosphere above Pakistan.

Satellite imagery of the South-Asia region reveals frequent outbreaks of dust, which have a large impact on Pakistan's climate and solar irradiance in the summer months. In South Asia, the highest values of mean mineral dust concentration - estimations based on atmospheric visibility - are found in Pakistan ([7] Rezazadeh et al., 2013). This highlights the importance of a thorough evaluation of the available aerosol datasets in the region. The main source of mineral aerosol in Pakistan can be traced back to the Sistan/Helmand river basin in western Afghanistan and Iran ([8] Alizadeh-Choobari et al., 2014). The newly calculated dataset will then be evaluated for various cloud conditions and a new cloud transmittance function will be implemented into a lookup table. If necessary this step will be applied to every single solar regime in Pakistan separately. Finally, the long term time series will be recalculated with the newly selected atmospheric data and cloud transmittance function. This is the long term time series best fitting the ground measurement data.

\section{Interim results}

\subsection{Satellite-based analysis}

During Phase 1, a 13-years satellite dataset (2000-2012) has been analyzed to develop a nonvalidated preliminary solar atlas showing multi-year means of $\mathrm{GHI}$ and $\mathrm{DNI}$, presented in Figure 2 and Figure 3 respectively. Irradiance values show high average values of DNI and $\mathrm{GHI}$ in most parts of Pakistan. In some areas irradiance sums are very high with only small intra-annual variability. A high level of solar insolation and low temporal variability of irradiance are appropriate preconditions for the development of solar energy systems in Pakistan. GHI shows highest values in southwest Pakistan, gradually decreasing to the north and northeast of the country with a minimum achieved in the Himalayan Mountains. 
Maximum values of just over $2300 \mathrm{kWh} / \mathrm{m}^{2}$ a are reached in the southwestern region of Balochistan. The estimated values only decrease gradually towards the northeast of the country. The annual mean value of GHI for whole Pakistan is $2071 \mathrm{kWh} / \mathrm{m}^{2}$, based on satellite estimations. The following preliminary estimates have been calculated using the MATCH data on a $0.5^{\circ} \times 0.5^{\circ}$ spatial resolution and daily temporal resolution (created by bilinear interpolation of original $1.9^{\circ} \times 1.9^{\circ}$ spatial resolution dataset).

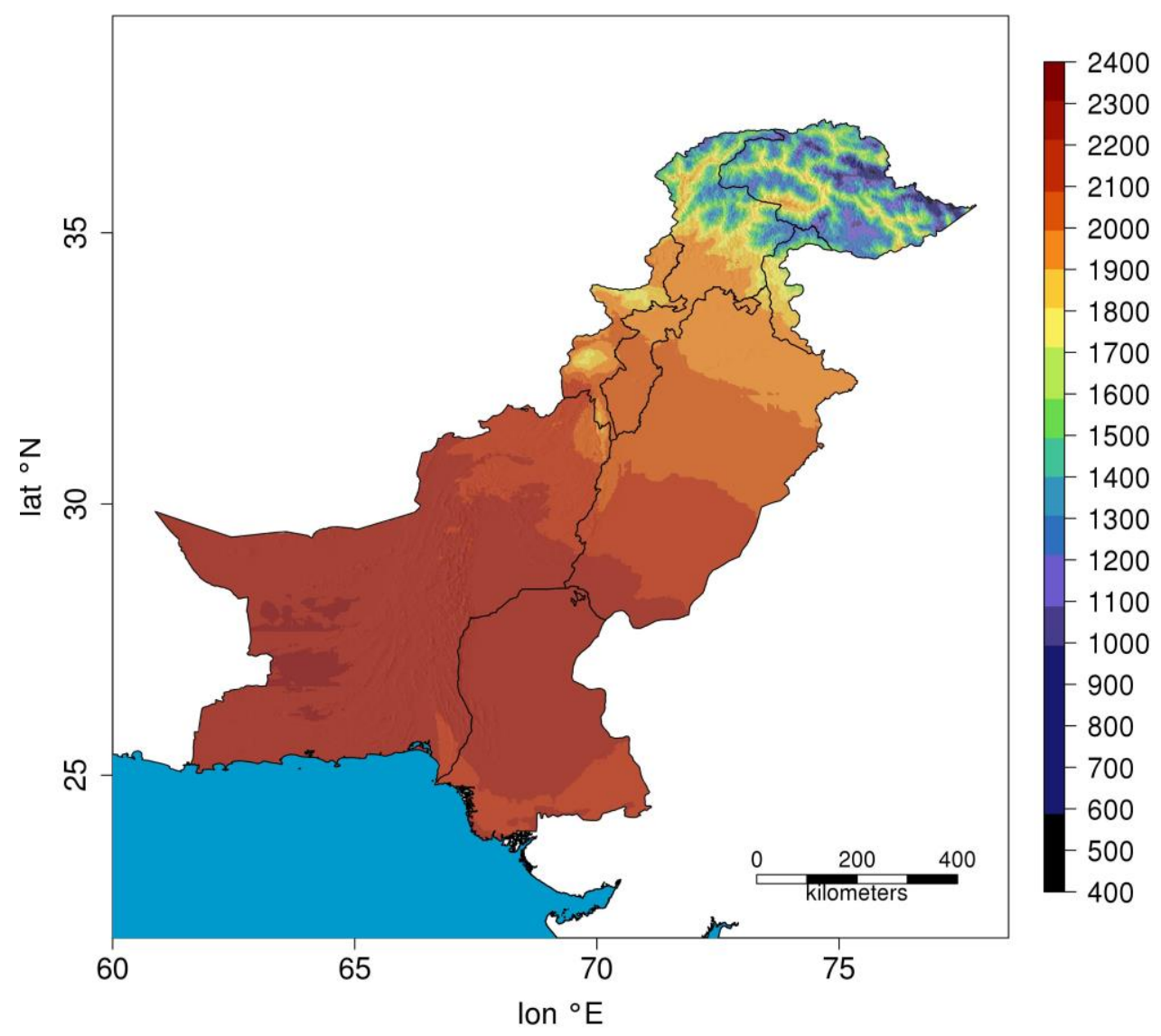

Figure 2: Multi-year mean (2000-2012) of annual Global Horizontal Irradiance (GHI) for Pakistan in $\mathrm{kWh} / \mathrm{m}^{2}$ based on satellite data.

From experience, DNI reaches highest values on dry plateaus or rock deserts when there is little or no dust advection from surrounding regions. Generally, high levels of DNI are available all over Pakistan, with the exception of the Himalayan Mountains. Estimated peak values, exceeding $2700 \mathrm{kWh} / \mathrm{m}^{2} \mathrm{a}$, can be found in northwestern Balochistan. These maximum values are comparable with the maximum values surrounding the Sinai Peninsula, which represents one of the top locations for irradiance in the MENA region. Besides the annual sums of Irradiance, it is important to consider the inter-annual as well as the intraannual availability of irradiance. The characteristic fluctuation of the annual sums of DNI for 
Pakistan is, like the sums for GHI, only small. With exception of Kyber Pakhtunkhwa and the Northern Regions, the average of the yearly sums is around $2100 \mathrm{kWh} / \mathrm{m}^{2}$ for most regions in the 13-year period.

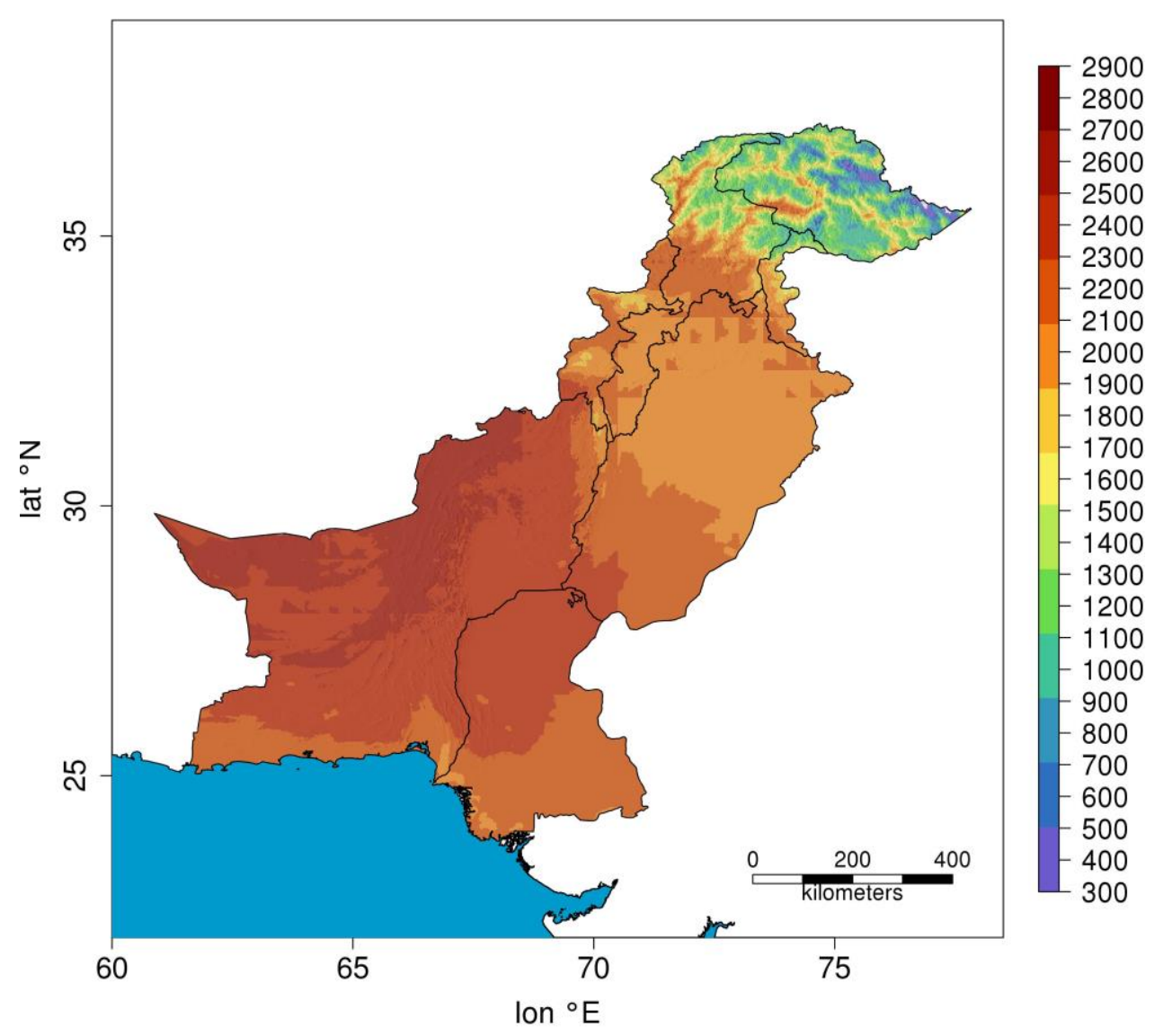

Figure 3: Multi-year mean (2000-2012) of annual Direct Normal Irradiance (DNI) for Pakistan in kWh/m² based on satellite data.

The frequencies for annual sums of $\mathrm{GHI}$ and DNI displayed in Figure 4 reveal the spatial distribution of the annual mean sum of the years 2000 to 2012 for Pakistan. The graph displays the frequency of occurrence of annual sums based on the number of grid pixels on the solar map covering the territory of the country. For $\mathrm{GHI}$ there is a frequency peak of values between $2150 \mathrm{kWh} / \mathrm{m}^{2}$ and $2350 \mathrm{kWh} / \mathrm{m}^{2}$, while the shallow but wider peak for DNI spreads between $2000 \mathrm{kWh} / \mathrm{m}^{2}$ and $2600 \mathrm{kWh} / \mathrm{m}^{2}$. For $\mathrm{GHI} 99.5 \%$ of all cells show values above $1500 \mathrm{kWh} / \mathrm{m}^{2}$ and $75 \%$ of all cells exceed the threshold of $2000 \mathrm{kWh} / \mathrm{m}^{2}$. For DNI, $90.8 \%$ of all pixel cells of the multi-year annual sum reach values above $1500 \mathrm{kWh} / \mathrm{m}^{2}, 83.5 \%$ exceed $2000 \mathrm{kWh} / \mathrm{m}^{2}$ and still $12.1 \%$ of the area reveals very high estimated values of more than $2500 \mathrm{kWh} / \mathrm{m}^{2}$. 
Frequency distribution of DNI and GHI

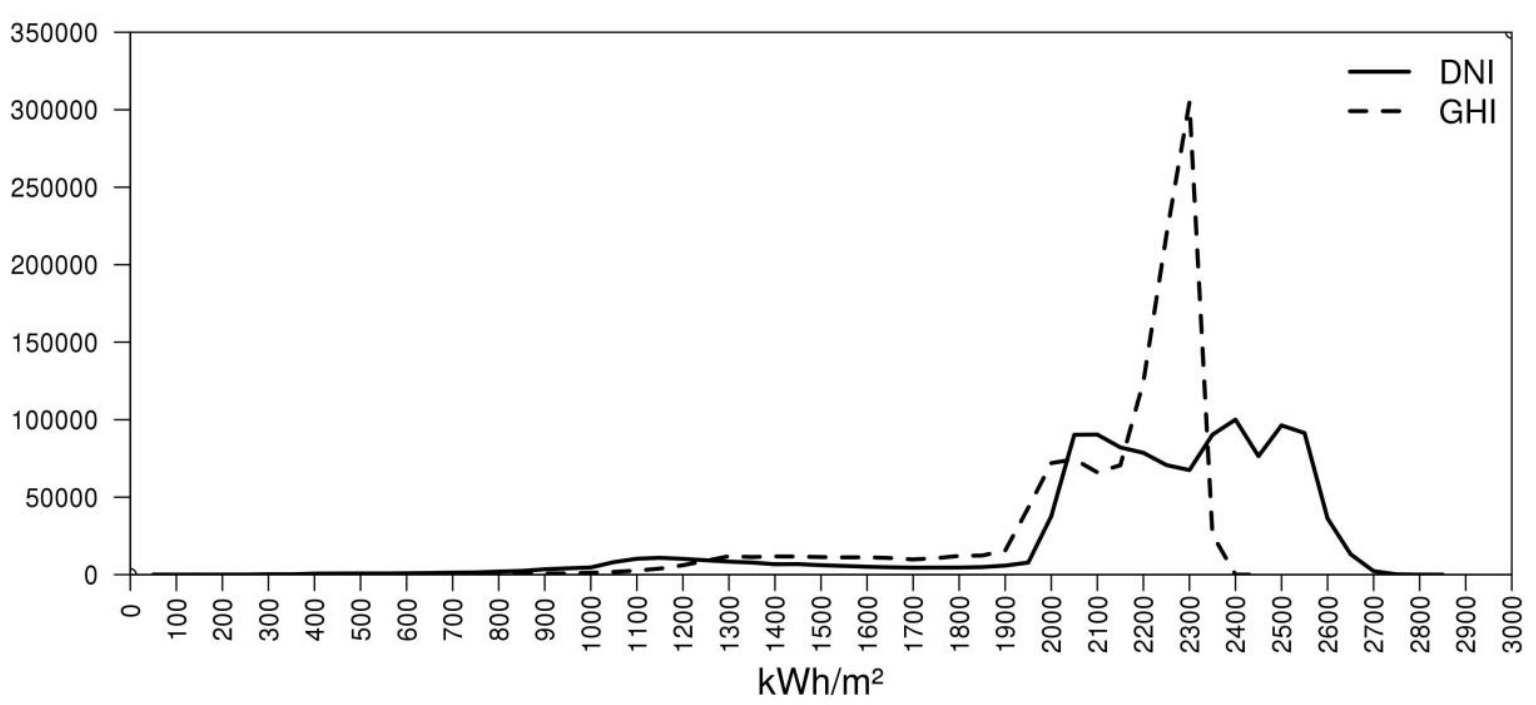

Figure 4: Multi-year mean sum frequency distribution of DNI and GHI in $50 \mathrm{kWh} / \mathrm{m}^{2}$ steps. Frequency displayed on y-axis based on satellite data.

\subsection{Ground measurements}

Surface measurement data is delivered regularly and shows good first results which can be owed to the thorough site selection process and to the reliable and regular maintenance visits by local staff. Figure 5 shows the intraday course of the surface irradiance of the high precision measurement site in Islamabad in a 10 minute temporal resolution. The example of January $14^{\text {th }}, 2015$ reveals an overcast morning in Pakistan with relatively high share of diffuse irradiance until midday. From noon onwards the sky clears up and direct part of irradiation increases, reaching a peak of $800 \mathrm{~W} / \mathrm{m}^{2}$ in the 10 minute-mean at $1 \mathrm{PM}$ local time, while the diffuse share of radiation drops from $377 \mathrm{~W} / \mathrm{m}^{2}$ in the morning to $111 \mathrm{~W} / \mathrm{m}^{2}$ at the same time. 


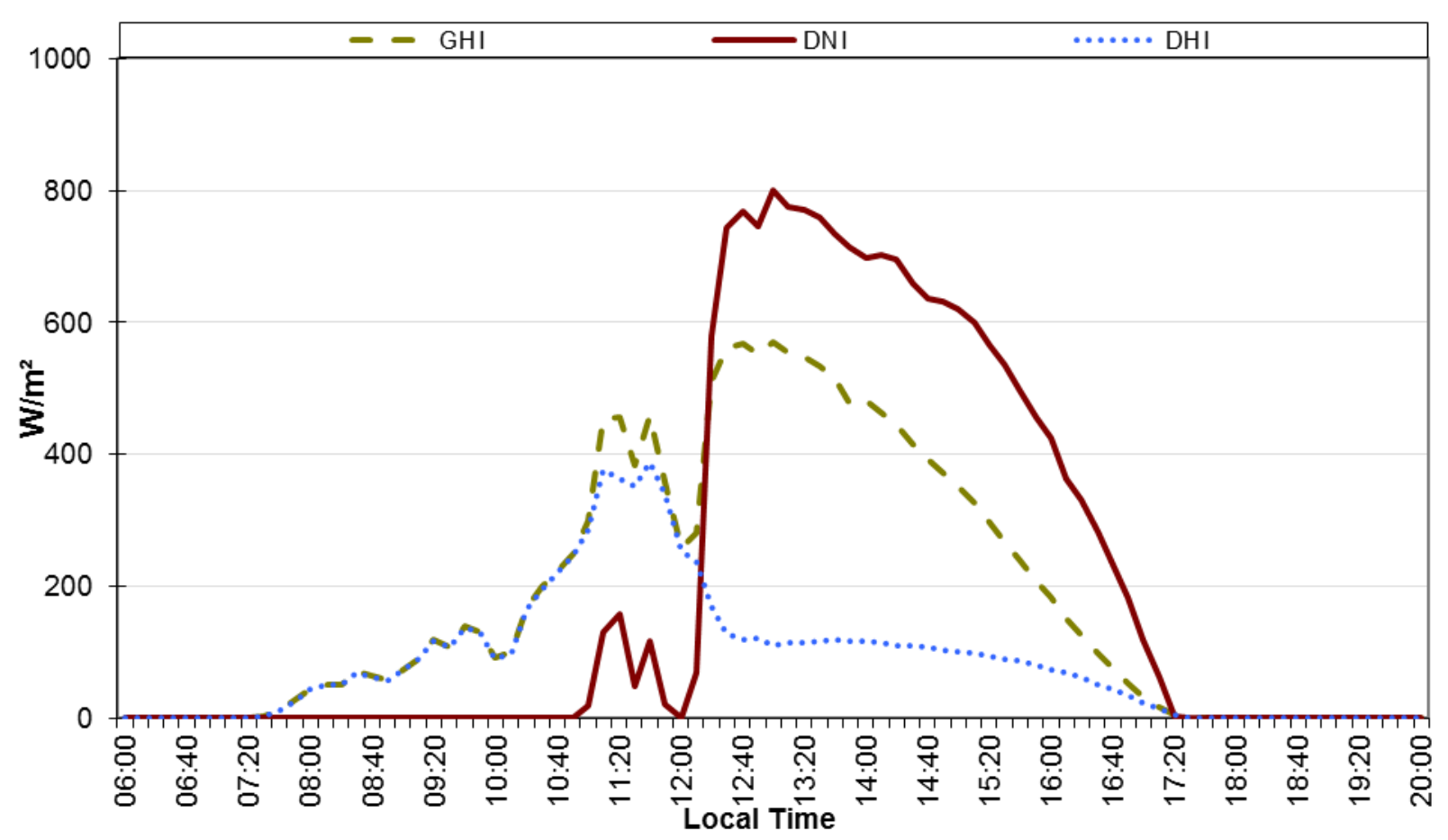

Figure 5: Irradiance (GHI, DNI and DHI) for Tier 1 meteorological station in Islamabad on January $14^{\text {th }} 2015$ in 10 min. resolution.

\section{Final Output}

Interim and final data will be disseminated by the World Bank GIS-team. The final validated dataset will be provided via the IRENA global atlas for renewable energy ${ }^{4}$, along with data from further country studies within the ESMAP framework, including solar, wind, biomass and resource maps of small hydro applications. Strict data policy will ensure homogeneous data quality provided to the atlas.

Following information will be provided:

- Digital data on monthly average daily totals for GHI, DNI and DIF in a gridded (GeoTiff) format covering Pakistan with a spatial resolution of 2,5 km x 2,5 km.

- Maps of long-term monthly and annual values of GHI, DNI, DIF, and GTI covering Pakistan

- Monthly reports and hourly values for the ground measurement sites.

\footnotetext{
${ }^{4}$ http://globalatlas.irena.org/ (02/2015)
} 
- Long-term (2000-2017) hourly time-series of GHI, DNI and DIF based on validated satellite data for the coordinates of ground measurements sites.

\section{Outlook and next steps}

The first measurement stations, including the two TIER 1 high-precision stations have been set up and are operational since October 2014. The measurement period within the project will continue for at least 24 months, with regular maintenance visits to the sites and interim validations of satellite outputs as soon as overlapping ground-measured data and modelled data are available. As a result from the careful site selection process involving local institutions, it is anticipated that the measurement stations are taken over by Pakistani institutions for further measurement continuation at the end of the project in 2017. Local staff will then be able to handle and interpret the existing satellite data for further scientific use and the data may contribute also to improve knowledge about climate change in Pakistan. Consequences of the global climate change are existent in Pakistan and may besides of socio-economic and environmental impact - influence the country's future solar potential. Therefore, microscale- and mesoscale climatic effects, like frequent dust storms ([7] Rezazadeh et al., 2013), influence of monsoon seasons ([9] Sarfaraz, 2007) or widespread winter fog ([10] Hameed et al., 2000), will also be considered in the study. Some stations are set up in regions that are influenced by at least one of these weather patterns. Dust storms are frequently affecting the measurement site planned in Nok Kundi, while the sites in Lahore and Islamabad are covered by winter fog in the winter months from time to time. The site in Quetta delivers significant data to validate clear sky cases as cloud cover will be presumably relatively low and the site is located $1600 \mathrm{~m}$ above sea level. Ultimately the validated dataset will be compatible with the IRENA Global Atlas data catalogue and the GIS layers shall be compatible with OGC standard web mapping services.

\section{Conclusion}

Within the World Bank's ESMAP Program a solar resource assessment project is conducted for Pakistan. Within the project presented in this article, satellite data and ground measurements are used to provide reliable and validated solar resource information to support country-driven efforts to improve renewable energy resource awareness and exploitation. Ground measurements of solar radiation provided during a 2-year measurement campaign at 9 selected sites in Pakistan together with satellite data will be used to establish freely available reliable and validate data on solar radiation for whole Pakistan. 
Preliminary results from phase 1 of the solar mapping project show a high potential for solar energy applications in Pakistan. Yearly sums of DNI and GHI exceed $2000 \mathrm{kWh} / \mathrm{m}^{2}$ in large parts of the country will give planners a variety of possibilities to install PV or CSP applications, even though some of the peak values can be found far away from urban conglomerations or electricity grid access. The high annual sums of GHI and DNI within Pakistan are auspicious at first view, but it has to be evaluated what the impact of intraannual fluctuations of irradiance will be. Seasonal variability can be expected in most regions, caused by increased dust storm activity in the south and west, optical thick clouds during summer monsoon along the Indus-river valley or attenuation of solar irradiance during winter-fog periods in the eastern and northeastern lowlands. Nevertheless, these regional fluctuations may be compensated by an effective energy mix from renewable energy sources dispersed throughout the country. This is where a comprehensive countrywide study as ESMAP's renewable energy mapping can deliver valuable results, as it considers not only solar energy, but also wind- and hydro energy within this project.

\section{Acknowledgements}

The study is being funded by the World Bank Group under contract \#7170053 and is undertaken in close coordination with Alternative Energy Development Board (AEDB), Government of Pakistan, the World Bank's primary Client country counterpart for this project.

The solar vendor consortium consists of the German Aerospace Center (DLR), CSP Services $\mathrm{GmbH}$ (CSPS), Ecofys and the local partner PITCO.

The authors would like to express their gratitude to the local partner PITCO; the universities at Islamabad, Lahore and Multan; the QA Solar Park in Bahawalpur for providing great assistance for the measurement campaign. 


\section{References}

[1] Adnan, S., Hayat Khan, A., Haider, S., Mahmood, R.: Solar energy potential in Pakistan, J. of Renew. and Sustainable Energy 2012, 4(3)

[2] Perez, R., Schlemmer, J., Moore, K., George, R.: Satellite Derived Resource Assessment in Afghanistan \& Pakistan in support of the USAID South Asia Regional Initiative 2007. NREL subcontract \# AEJ65517201.

[3] Perez, R., Seals, R., Zelenka, A.: Comparing satellite remote sensing and ground network measurements for the production of site/time specific irradiance data. Solar Energy 1997, 60: 89-96

[4] Hammer, A., Heinemann, D., Hoyer, C., Kuhlemann, R., Lorenz, E., Mueller, R.W., Beyer, H.G.: Solar energy assessment using remote sensing technologies 2003, Remote Sens. of Environ., 86: 423-432

[5] Rigollier, C., Lefèvre, M., Wald, L.: The method Heliosat-2 for deriving shortwave solar radiation from satellite images, Solar Energy 2004, Vol. 77, Issue 2: 159-169

[6] Cano, D., Monget, JM., Albuisson, M., Guillard, H., Regas, N., Wald, L.: A method for the determination of the global solar radiation from meteorological satellite data, Solar Energy 1986, 37: 31-39

[7] Rezazadeh, M., Irannejad, P., Shao, Y.: Climatology of the Middle East dust events, Aeolian Res. 2013, Vol. 10: 103-109

[8] Alizadeh-Choobari, O., Zawar-Reza, P., Sturman, A.: The "wind of 120 days" and dust storm activity over the Sistan Basin, Atmos. Research 2014, Vol. 143: 328-341

[9] Sarfaraz, K.: Monsoon dynamics: Its behavioral impact in Pakistan's Perspective, Pakistan J. of Meteorol. 2007, Vol. 4 Issue 7: 55-73

[10] Hameed, S. , Ishaq Mirza, M., Ghauri, B. M., Siddiqui, Z. R., Javed, R., Khan, A. R., Rattigan, O. V., Qureshi, S., Husain, L.: On the widespread winter fog in northeastern Pakistan and India. Geophys. Research Letters 2000, Vol. 27, No. 13: 1891-1894 